\title{
ILUSÃO DIGITAL E A AUTODETERMINAÇÃO DEMOCRÁTICA NAS REDES SOCIAIS
}

\section{Thiago Alves Feio ${ }^{1}$ \\ Patricia Kristiana Blagitz Cichovski ${ }^{2}$}

Resumo: O potencial democrático foi expandido com o avanço da tecnologia, entretanto, pode se mostrar apenas em termos formais. $O$ trabalho questiona em que medida as redes digitais podem propiciar o exercício substancial da democracia no Brasil, frente ao ilusório controle sobre acesso de dados na rede e aos déficits de formação no País? O objetivo é analisar possibilidade do exercício adequado da democracia no Brasil, com o uso de redes sociais. A metodologia adotada foi a revisão bibliográfica e o método foi hipotético-dedutivo. Há graves obstáculos ao exercício substancial da democracia.

Palavras-Chave: Democracia; Exercício Substancial; Internet; Redes Sociais; Capacidade.

\section{DIGITAL ILLUSION AND DEMOCRATIC SELF-DETERMINATION IN SOCIAL NETWORKS.}

Abstract: The democratic potential has been expanded with the advancement of technology, however, can only be shown in formal terms. The paper questions the extent to which digital networks can foster the substantial exercise of democracy in Brazil, in the face of the illusory control over data access in the network and the lack of training in Brazil? The objective is to analyze the possibility of the adequate exercise of democracy in Brazil, with the use of social networks. The methodology adopted was the bibliographic review and the method was hypothetico-deductive. There are serious obstacles to the substantial exercise of democracy.

Key-words: Democracy; Substantial Exercise; Internet; Social networks; Capacity.

\section{INTRODUÇÃO}

$\mathrm{O}$ avanço da tecnologia trouxe, em princípio, um enorme potencial para revolucionar intervenção democrática dos cidadãos no processo de formação da vontade do povo e de tomada de decisões políticas. Assim, o indivíduo deixa a posição de mero espectador e passa a ser ator dos debates políticos, podendo expressar suas opiniões.

\footnotetext{
${ }^{1}$ Mestre em Direito e Políticas Públicas pelo CESUPA. MBA em Direito do Trabalho e em Gestão Empresarial, pela FGV. 1 Livro e 9 artigos publicados. Endereço: Rua dos Tamoios 1457. Batista Campos, CEP: 66033-172. E-mail: thiagoalvesfeio@hotmail.com ; Site: www.thiagofeio.com

2 Doutora em Direito pela PUC/SP. Professora de Graduação e do Programa de Pós-Graduação Stricto e Lato Sensu em Direito do CESUPA. Professora da FAMAZ. Diretora do Departamento de Ensino e Pesquisa da Escola Superior da Magistratura do Estado do Pará. Endereço: Travessa Apinages 630, CEP: 66033-170. E-mail: p-blagitz@uol.com.br
}

Revista de Teorias da Democracia e Direitos Políticos | e-ISSN: 2525-9660 | Porto Alegre | v. 4 | n. 2 | p. $23-44$ | Jul/Dez. 2018 
Entretanto, para além da definição formal, o conceito de democracia possui alguns requisitos, como uma definição variando de acordo com a sociedade, a autodeterminação dos cidadãos, a correspondência das decisões políticas com os anseios da sociedade e a prevalência do interesse público. A partir da teoria de Amartya Sen, que pressupõe para a livre utilização de um direito o requisito da presença das condições necessárias para o exercício adequado do mesmo, podemos definir que a democracia substancial só é possível caso sejam proporcionadas as condições necessárias aos cidadãos para seu exercício. Caso não sejam proporcionadas tais condições, pode causar um efeito diverso do esperado, expondo o cidadão à uma avalanche de informações, apresentando "verdades absolutas artificiais" que comprometem suas ideias, e condicionando o conteúdo a que o mesmo possui acesso para influenciar em sua percepção.

Esse cenário apresenta maior gravidade quando inserido no contexto brasileiro, que possui uma população com baixo nível de instrução, pouca habilidade computacional e altamente suscetível a clamores populares.

A pergunta norteadora do trabalho se apresenta da seguinte forma: Em que medida as redes digitais podem propiciar o exercício substancial da democracia no Brasil, frente ao ilusório controle sobre acesso de dados na rede e dos déficits de formação no País?

Portanto, o presente estudo possui o objetivo de realizar uma análise crítica acerca possibilidade do exercício substancial da democracia no Brasil, a partir do uso das redes digitais.

A pesquisa desenvolvida possui caráter teórico, adotando por metodologia a revisão bibliográfica, que compreende a utilização de livros, artigos e pesquisas, nacionais e estrangeiros. O método empregado foi hipotético-dedutivo, empreendendo uma pesquisa exploratória da doutrina especializada.

Para solidificar os conceitos a serem utilizados neste trabalho, é necessário definir primeiro o conceito de democracia, para depois estabelecer alguns requisitos para seu exercício efetivo (de acordo com Amartya Sen). Em seguida, será realizada uma análise da possibilidade de seu exercício adequado no Brasil, a partir das dificuldades apresentadas pelo uso das redes digitais, ou se esse exercício substancial constitui apenas uma ilusão digital.

\section{DEMOCRACIA}

Revista de Teorias da Democracia e Direitos Políticos | e-ISSN: 2525-9660 | Porto Alegre | v. 4 | n. 2 | p. $23-44$ | Jul/Dez. 2018 
Para possibilitar a análise do objeto desse estudo, se faz necessário a principio definir o conceito de democracia para então relacionar com as ideias de Amartya Sen sobre seu exercício e, posteriormente, avaliar seu estado no universo das redes socais. Serão tomadas como base as concepções de Jürgen Habermas e Ronald Dworkin sobre o tema para nortear o debate.

O primeiro autor, Jürgen Habermas, possui uma concepção de democracia voltada para a legitimidade a partir da efetivação dos valores constitucionais e para noção de bem comum.

Para o autor, a Constituição deveria ser a o ponto de separação entre os interesses privados e o bem comum. Nesse cenário, a política seria encarregada da tarefa de concretizar os objetivos e valores positivados na Constituição, por possuírem uma visão ampla e orientada para o futuro, visando atingir esses objetivos. A garantia dos direitos fundamentais exige que o Estado realize ações planejadas, que visem à preparação de infraestruturas e bases que possam concretizar esses direitos. Essa atitude só pode ser tomada de forma coordenada pela esfera estatal, com planejamentos de longo prazo (HABERMAS, 1997, p. 304-306). A legitimação dos poderes Legislativo e Judiciário é concedida pela Constituição de forma distinta. Ao Judiciário é concedida a função de aplicar o direito num determinado caso. Ao Legislativo é destinada a tarefa de organizar um sistema de direitos, baseado nos preceitos constitucionais, visando atingir seus objetivos políticos. A Constituição não possui a finalidade de ditar o modo de vida da sociedade de forma única e fechada. Ela se destina a formalizar um conjunto de decisões e procedimentos políticos que visam proporcionar que os próprios cidadãos possam determinar seu modo de vida. $\mathrm{O}$ modo de vida de uma sociedade muda de acordo com o tempo, e a Constituição deve permitir que seja implementado esse modo de vida sem grandes revoluções (HABERMAS, 1997, p. 324-326).

O processo democrático possui a função de programar o Estado para concretizar o interesse da sociedade. O Estado aparece como a entidade administrativa que irá organizar a vida social, com base na vontade pública. A política tem a tarefa de impor a vontade social ao Estado, para que esse possa ter conhecimento dessa vontade e, a partir dela, organizar as políticas públicas que concretizaram essa vontade. Assim, o Estado não é resultado de uma formula pré-estabelecida, mas sim o resultado da autodeterminação dos cidadãos. O Estado só

Revista de Teorias da Democracia e Direitos Políticos | e-ISSN: 2525-9660 | Porto Alegre | v. 4 | n. 2 |

p. $23-44$ | Jul/Dez. 2018 
se legitima se proteger esses valores, pois a formação do Estado se baseia principalmente na garantia da formação e proteção das vontades populares, e posteriormente na proteção dos direitos individuais (HABERMAS, 1997, p. 332-335). Da mesma forma, o direito em uma sociedade deve estar em conformidade com os princípios morais da mesma, para que seja considerado verdadeiramente válido. No entanto, muitas vezes mesmo com o discurso de respeito ao pluralismo social, ficam ocultos determinados interesses e valores axiológicos que tentam predominar, mas não corresponde a vontade popular geral. Esses interesses e valores axiológicos constantemente entram em conflito, precisando de um jogo de concessões para aceitar o resultado das divergências, mesmo que esse resultado coincida com a vontade popular (HABERMAS, 1997, p. 350-351).

Portanto, para o autor, a conceito de democracia possui alguns requisitos necessários para conceder legitimidade ao governo: a inexistência de uma forma pré-definida de governo, irá variar de acordo com a sociedade em questão; a autodeterminação dos cidadãos; a efetivação da vontade social, frente aos interesses particulares; e a garantia de formação e proteção dessas vontades populares.

Outro doutrinador que procura conceituar democracia é Ronald Dworkin. Para o autor a concepção de democracia é interpretativa, ou seja, não há uma definição fechada e consensual sobre o instituto.

Segundo o autor, cada sociedade deve escolher a interpretação que melhor se adequa ao seu contexto, existindo dois modelos que podem ser utilizados como base para identificação da democracia. O primeiro seria a concepção de maioria, ou maioritária, em que a legitimidade democrática se evidencia quando as decisões fundamentais de um governo correspondem a vontade da maioria da sociedade, em um sistema representativo. O segundo modelo, denominado de parceria, a legitimidade democrática não está atrelada a representação da maioria, visto que presa pelos representantes que atuam preocupados com o conjunto social, que trata todos os indivíduos como parceiros. Existe uma diferença principal entre os dois modelos, enquanto o modelo majoritário fundamenta sua legitimidade em bases formais, por outro lado, o modelo de parceira busca legitimidade em um aspecto material (DWORKIN, 2012, p. 390-392).

Em outros termos, a concepção de Dworkin sobre democracia possui um conceito aberto, que varia de acordo com o contexto da sociedade que se analisa. Para se adequar a 
essa abordagem o autor propõe um modelo, representativo a partir da vertente majoritária, em que legítimo é aquele que foi votado pela maioria de acordo com o procedimento estabelecido, e outro modelo, de parceira, que se baseia na correspondência efetiva das decisões com os anseios sociais e na preocupação dos governantes com o conjunto social, atuando como parte de um todo.

Ao tentar definir o melhor, entre dois modelos, Dworkin afirma depender o contexto da sociedade, pois não há uma resposta definida a priori. Porém o autor cita alguns aspectos importantes, em comum, para o funcionamento dos modelos, como: a existe de uma imprensa independente e forte, para proteger a sociedade e fiscalizar o interesse público das ações governamentais; uma tradição e estabilidade democrática, que possibilite os grupos sociais postularem seus interesses; e o exercício de liberdades políticas e possibilidade de participação efetiva nas decisões do governo (DWORKIN, 2012, p. 393-394).

$\mathrm{O}$ autor entende que o funcionamento de qualquer um dos dois modelos de democracia é necessário que estejam presentes alguns aspectos, para proporcionar a correspondência entre o as decisões políticas e os anseios da sociedade. Esse entendimento se firma na ideia de que, mesmo no modelo formal maioritário, devem ser combatidas as tiranias e o atendimento somente o interesse de poucos.

Para Dworkin, existe ainda um requisito principal para que os modelos democráticos sejam legítimos, que a distribuição do poder político possibilite o respeito isonômico aos setores da sociedade. Esse requisito abrange, ainda, a proibição de discriminações eleitorais, ou seja, todos devem poder votar e ser votados, visando abarcar todo o conjunto no cenário político e, portanto, e tentar conceder maior legitimidade as decisões políticas (DWORKIN, 2012, p. 400-402)

Portanto, a partir das definições de Jürgen Habermas e Ronald Dworkin, podemos extrair alguns preceitos, gerais e comuns aos dois autores, do conceito de democracia. $\mathrm{O}$ primeiro diz respeito à variação que o conceito sofre, de acordo com a sociedade em questão. O segundo é a autodeterminação dos cidadãos, sendo requisito que os mesmos tenham capacidade para exercer a democracia. $\mathrm{O}$ terceiro preceito é a correspondência das decisões políticas com os anseios da sociedade, não podendo privilegiar interesses particulares ou de poucos. O quarto requisito se refere à prevalência do bem comum, que preza pelo interesse público.

Revista de Teorias da Democracia e Direitos Políticos | e-ISSN: 2525-9660 | Porto Alegre | v. 4 | n. 2 | p. $23-44$ | Jul/Dez. 2018 
Revista de Teorias da Democracia e Direitos Políticos | e-ISSN: 2525-9660 | Porto Alegre | v. 4 | n. 2 | p. $23-44$ | Jul/Dez. 2018 


\section{A EXPANSÃO DEMOCRÁTICA COM A REDE DIGITAL}

A rede de computadores oferece a sociedade um enorme potencial de real participação no processo democrático. Esse potencial, caso bem conduzido, possibilitaria uma revolução na forma democrática de intervenção dos cidadãos no processo de formação da vontade do povo e de tomada de decisões políticas. Com o surgimento da Internet, se criou uma enorme expectativa quanto a expansão do exercício da democracia pela sociedade como um todo. Essa participação havia estado adormecida por longos tempos e, finalmente, haveria porta de acesso para um novo "florescer democrático".

No entender de Maia, a internet facilita a interação entre os usuários e possibilita a mobilização mais ágil de multidões, reunidas com um objetivo comum. A rede oferece espaços que possibilitam a organização de encontros em massa e do debate plural sobre assuntos relevantes. Essa organização da sociedade poderia, em tese, funcionar de forma livre, longe dos controles e limitações das instituições públicas e privadas (MAIA, 2016, p. 113116). Nesse sentido, os indivíduos têm experimentado a oportunidade de criar e participar de forma mais efetiva, seja produzindo seu próprio conteúdo ou opinando sobre postagens de terceiros (MAIA, 2016, p. 164).

Para Castells, esse pensamento se baseia em fatores como o acesso as informações, que possibilitaria o cidadão estar tão bem informado quanto seu representante, e a interação com seus representantes, facilitada de forma nunca imaginada, por conta de a Internet encurtar as distâncias físicas. Outro fator importante seria a viabilidade de a sociedade fiscalizar o governo, pois, com a possibilidade de divulgação de informações de interesse público e de contato direito com os governantes, o cidadão seria capaz de participar ativamente da vida política. Nesse cenário, os partidos políticos migraram suas campanhas eleitorais para o mundo virtual, a fim de potencializar o alcance de sua influência e reduzir o custo de suas campanhas, apesar de continuarem a atuar nos meios de comunicação tradicional (CASTELLS, 2003, p. 18-19).

No entanto, apesar de ser um ambiente livre, os poderes institucionalizados e os agentes formadores de opiniões atuam de forma incisiva na rede digital. As instituições e indivíduos detentores de influência interferem na internet com grande importância, direcionando e mobilizando o pensamento dos usuários (MAIA, 2016, p. 118-128).

Revista de Teorias da Democracia e Direitos Políticos | e-ISSN: 2525-9660 | Porto Alegre | v. 4 | n. 2 |

p. $23-44$ | Jul/Dez. 2018 
No mesmo sentido, para Castells seria uma visão utópica esperar que a Internet resolvesse a desconfiança da sociedade em relação a política e a crise de representatividade, instauradas mundialmente nos últimos tempos. Talvez o movimento tenha sido inverso, tendo em vista a atuação burocrática e displicente que os políticos transportaram das campanhas para o ambiente virtual e os internautas de posse de maior esclarecimento acaba por desprezar e se desacreditar dos conteúdos de cunho político. Outro fator é a utilização da Internet, por parte dos políticos, para atacar e difamar o concorrente, em vez de expor suas ideias e formas de governo. Nesse sentido, “A Internet não pode fornecer um conserto tecnológico para a crise da democracia" (CASTELLS, 2003, p. 19-20). Em verdade, o mundo virtual se transformou em "uma plataforma de lançamento mais ampla para a política do escândalo. $\mathrm{O}$ problema, naturalmente, não está na Internet, mas no tipo de política que nossas sociedades estão gerando" (CASTELLS, 2003, p. 21).

O mundo virtual potencializa a disseminação das informações e acontecimentos, sendo povoado, não somente por pessoas físicas, mas também por corporações e entidades, que possuem grande renome no mundo real e transportam para a Internet. Essas autoridades passam a ser formadores de opinião no ambiente virtual, ao lado de celebridades e políticos, ampliando de forma exponencial seu alcance, independente da veracidade ou relevância de suas palavras, pois deixam de depender dos meios convencionais de informação (BRISOLA, 2016, p. 69).

A partir desse pensamento, podemos visualizar que o movimento foi contrario ao projetado. Aqueles que já detinham poder de influência tiveram seu alcance ampliado pela rede, que facilitou sua expansão por um meio mais amplo, prático e barato que os meios de comunicação convencionais. Por outro lado, a Internet não modificou o comportamento da sociedade, mas, simplesmente, potencializou o comportamento atual, através reprodução de suas práticas em um ambiente mais amplo e protegido pelo anonimato. Outro ponto, é que a maioria dos usuários possui o comportamento de consumir conteúdo pronto, sem averiguar sua procedência, e repassar sem a devida reflexão.

Assim, a Internet, que deveria ser um importante canal de acesso à informação e de debate democrático, acaba por se tornar um ambiente hostil e de grande quantidade de informações desencontradas, que afasta ainda mais o cidadão do exercício da democracia e do contato com seus representantes.

Revista de Teorias da Democracia e Direitos Políticos | e-ISSN: 2525-9660 | Porto Alegre | v. 4 | n. 2 | p. $23-44$ | Jul/Dez. 2018 
Outro ponto importante se mostra com relação a intervenção do indivíduo no diálogo político da sociedade e da possibilidade de influência. Com a difusão do acesso a Internet no Brasil, em especial das redes sociais, o indivíduo deixa a posição de mero espectador dos debates políticos para ator com possibilidades de expressar seus ideais e opiniões, acerca dos temas polêmicos, em tempo real.

Essa inovação permitiu diversas alternativas de organização da civil para o debate, sendo considerada uma abertura para um exercício maior da democracia e para a construção de pontes entre grupos, até então consideradas impossíveis. No entanto, o simples acesso a informação não basta para criar a participação efetiva dos indivíduos no processo de formação da vontade social. Se fazem necessárias proporcionar condições para a realização de um diálogo produtivo entre os atores, que possibilite a influência real dos cidadãos (BRISOLA, 2016, p. 54).

Nesse sentido, a partir da conceituação de democracia e do estabelecimento de seus preceitos gerais, o momento é de definir as condições essenciais para seu exercício, visando analisar, posteriormente, se o cenário de rede sociais no contexto brasileiro possibilita o processo democrático. Para definir essas condições, serão utilizados os pensamentos do doutrinador Amartya Sen acerca de liberdade e capacidade para o exercício de direitos.

Para o autor, não basta que exista um direito positivado em uma determinada sociedade para que o indivíduo seja detentor daquele direito, sendo necessário que possua liberdade para utilizar o mesmo. A liberdade, nesse ponto, se refere à ausência de restrições que impossibilitem o exercício pleno daquele direito. Aqui podemos citar como restrições ao cidadão para exercer a democracia: a ausência de poder econômico; ausência de poder político para influenciar nas decisões, como violação ao voto e os outros meios de participação; ausência de oportunidades para alcançar seus objetivos e concretizar suas atividades planejadas; ausência de possibilidade para seu desenvolvimento; e cerceamento de suas capacidades (SEN, 2000, p. 29-33).

A ideia central dessa primeira abordagem é de que não basta editar leis que preveem certos direitos, se os mesmos não forem acompanhados de liberdades para seu exercício. Ou seja, além de prever o direito, o Estado deve procurar não cercear ou limitar demais a liberdade de efetivação dos mesmos. O pensamento segue a trilha de que não basta estar formalmente previsto, o direito tem que ser possível na prática.

Revista de Teorias da Democracia e Direitos Políticos | e-ISSN: 2525-9660 | Porto Alegre | v. 4 | n. 2 |

p. 23-44 | Jul/Dez. 2018 
Em uma segunda linha de abordagem, Amartya Sen aprofunda seu raciocínio e adiciona, para o exercício de um direito, o requisito da capacidade. Nesse contexto, além as condições citadas na primeira abordagem, o cidadão precisa ter capacidade para o exercício do direito, no sentido de que o indivíduo deve possuir as condições e atributos necessários para o exercício pleno do direito. Podem ser citados como exemplo de condições para o exercício: a instrução básica; escolaridade; ausência de acesso a meios de debates políticos; e ausência de amplo acesso a informações, tanto informações públicas quanto meios independentes de informação (SEN, 2000, p. 47-50).

A segunda abordagem do autor amplia seu entendimento acerca do necessário para o exercício de um direito. Nesse ponto, o indivíduo deve, não só ter o direito positivado e a ausência de limitações e restrições a efetivação desse direito, mas também, possuir as condições necessárias para exercer o direito de forma minimamente aceitável.

Em suma, a teoria de Amartya Sen sobre liberdade e capacidade, oferece uma abordagem das condições reais que o indivíduo possui para exercer, na prática, um direito que lhe foi oportunizado na legislação.

A partir de uma relação com o tópico anterior, em que ficou definido como requisitos da democracia a autodeterminação dos cidadãos e a correspondência das decisões políticas com os anseios da sociedade, podemos definir que o exercício da democracia só é possível caso sejam proporcionadas as condições necessárias aos cidadãos para seu exercício, a partir da teoria de Amartya Sen. Em termos práticos, essa afirmação induz a ideia de que para o exercício da democracia é necessário que a população possua instrução básica, escolaridade, acesso a meios de debates políticos e amplo acesso a informações verdadeiras, que possibilite a sua capacidade de intervir nas decisões políticas e de formação de uma opinião livre de influências e barreiras. Nesses termos, é necessária uma reflexão acerca da existência dessas condições frente ao ativismo político através das ferramentas de redes sociais.

Em outros termos, o fato de estar normatizada a liberdade ao exercício da democracia e o acesso aos meios digitais se quer induz à uma democracia formal, visto que, diante da atuação de inteligências artificiais e outros fatores, a simples possibilidade de acesso a rede não garante a real participação, ou seja, há apenas a possibilidade de exercer o papel democrático (um potencial). Logo, para que essa democracia possa se efetivar em termos substancias, se faz necessário analisar outros fatores imprescindíveis para esse exercício.

Revista de Teorias da Democracia e Direitos Políticos | e-ISSN: 2525-9660 | Porto Alegre | v. 4 | n. 2 | p. $23-44$ | Jul/Dez. 2018 
A partir da teoria de Amartya Sen, o principal elemento para a democracia seria a capacidade para exercer esse direito no meio digital. Para possuir essa capacidade, além de outros elementos, é necessário um dos fatores definidos basilares da democracia no tópico anterior, a autodeterminação dos povos. Portanto, é requisito necessário para exercer de forma substancial a democracia a capacidade de autodeterminação, visando a atuação consciente e livre de influências no meio digital.

\section{DIFICULDADE DEMOCRÁTICA NA INTERNET}

Definido o exercício substancial da democracia como: a reunião das condições necessárias para seu exercício, de modo a possibilitar o real poder de influência nas decisões políticas, possuindo capacidade para influenciar, e que essas decisões correspondam com os anseios da sociedade e prevalência do interesse público. De posse desse conceito, cabe agora analisar como esse exercício pode se desenvolver no País, a partir das dificuldades apresentadas pelas redes sociais.

Para tanto, serão apresentadas quatro dificuldades encontradas no ambiente virtual para embasar a análise. A primeira diz respeito à capacidade real de os usuários participarem na rede. A segunda é o feed de conteúdo dos perfis das redes sociais e sua forma de comportamento, a partir do programa de gerenciamento. A terceira é a utilização de robôs na internet, contas autônomas programadas para se passar por usuários normais e apresentar conteúdo em massa. A quarta se relaciona com a utilização de dados dos usuários para encaminhar mensagens direcionadas de acordo com o perfil dos mesmos. Após a apresentação será possível analisar o exercício da democracia na rede.

\subsection{CAPACIDADE DE PARTICIPAÇÃO NA REDE}

A primeira dificuldade diz respeito a capacidade de interagir na internet para participar de forma minimamente aceitável, se fazendo necessário possuir a competência para utilizar a rede, uma espécie de graduação no ambiente virtual.

Para tanto, o ator deve aprender a utilizar de forma adequada a ferramenta que lhe é apresentada e o modo tratar as informações que lhe são disponibilizadas, ou impostas. O

Revista de Teorias da Democracia e Direitos Políticos | e-ISSN: 2525-9660 | Porto Alegre | v. 4 | n. 2 | p. $23-44$ | Jul/Dez. 2018 
conhecimento deve ser construído a partir das escolhas do ator, e não de quem disponibiliza as informações. Assim, além do acesso as informações, o cidadão deve possuir a competência para utilizar de forma crítica, sem se perder no excesso de informações e nos mecanismos de influência (BRISOLA, 2016, p. 73-75) As redes digitais podem ser importantes campos de difusão de informações e diálogos, que em um segundo momento pode ampliar o debate democrático. Essa ferramenta rompe barreiras de tempo, espaço e dependência dos veículos de comunicação, que restringiam o debate aberto sobre os temas (BRISOLA, 2016, p. 86-87).

O livre acesso à rede não importa em participação democrática se não vier estiver acompanhada da capacidade para utilizá-la de forma adequada. Essa participação só se mostra efetiva quando o cidadão possui capacidades para influir de forma real no processo democrático. A facilidade das redes informacionais não surte o efeito devido se não for acompanhado das condições para o exercício consciente do debate. O simples acesso a esse universo acaba criando reprodutores de senso comum, que apenas compartilham "verdades absolutas" criadas com o objetivo de manipular a opinião pública. Esse tipo de atuação acaba poluindo a rede, sem contribuir de modo produtivo para a evolução do debate.

Assim, no contexto social brasileiro a situação se mostra preocupante, por conta da ausência de preparação dos usuários para utilizar o sistema, tendo em vista que a sociedade acessa a Internet de forma cada vez mais precoce, gerando jovens que estão altamente suscetíveis a influências desse ambiente e a informações falsas, sem o mínimo de preparação ou habilidade para a utilização. $\mathrm{O}$ fato de manusear de forma precária a ferramenta não induz a ideia de que está preparado de forma adequada para tanto. A falta preparação deixa o indivíduo sem defesas para os conteúdos nocivos e as influências presentes na rede.

\subsection{REDES SOCIAIS E O FEED DE CONTEÚDO}

A segunda dificuldade se refere ao acesso as informações nas redes sociais. Esse acesso, via de regra, se dá a partir de um feed, que apresenta os principiais conteúdos da rede a qual o perfil do usuário está conectado. O foco estará no modo como o programa que controla esse feed se comporta.

As redes sociais têm se tornado importante ambiente para o amplo debate de diversos assuntos da sociedade, que contribuem para o debate democrático, de forma positiva e 
negativa. O mundo virtual passou a ser a principal ferramenta de disseminação de informações no mundo globalizado, deixando para trás importantes meios de comunicação.

Para servir de base para o estudo foi escolhido o grupo Facebook, por ser constituído de diversas redes importantes, como a rede social Facebook, o Whatsapp e o Instagram. Dessa forma, se caracteriza como grupo que possui a maior parte das plataformas com maior utilização atualmente.

Em especifico, a rede social Facebook se caracteriza por armazenar o perfil pessoal, ou profissional, e apresentar informações de perfis e paginas conectados aquele em forma de feed (ou timeline), que seria uma pagina de apresentação de informações em forma de cascata. Dessa maneira, a empresa "obtém um histórico completo da vida de cada cidadão, bem como seus interesses, valores e relações sociais, possibilitando análises multidimensionais e detalhados perfis de grande interesse comercial" (MACHADO; MORETTO, 2015, p. 113). A plataforma armazena uma grande quantidade de dados, a partir de toda a interação de cada usuário realiza, cada curtida, comentário e mídia que o usuário publica ou tem contato. Os dados coletados são utilizados de acordo com os interesses da empresa, que pode utilizar para tornar a plataforma mais eficiente, bem como fornecer e vender a terceiros com fins econômicos (MACHADO; MORETTO, 2015, p. 118).

Nesse sentido, se faz necessário estabelecer, desde logo, que o grupo Facebook não possui objetivo a prevalência do interesse público, a plataforma possui interesses privados e econômicos. Portanto, toda a interação realizada em seus domínios pode ser comercializada de acordo com os interesses da empresa. A partir dessa premissa, é importante abordar a questão do feed da plataforma.

A timeline ou feed do usuário é apresentada com base em diversos fatores, sendo personalizado para cada perfil a partir de sua interação nas redes pertencentes ao grupo. Em geral, o conteúdo é mostrado de com as interações do usuário, do número de curtidas, comentários e compartilhamentos da publicação, entre outros fatores. Ou seja, de forma genérica, de acordo com as interações do perfil, as publicações com maior repercussão na rede aparecem com maior destaque ao usuário, e tendem a alavancar sua visibilidade. Essa forma de apresentar o conteúdo vai se adaptando com o decorrer do tempo, a partir da atuação do usuário (MACHADO; MORETTO, 2015, p. 125). 
Entretanto, essa é apenas uma indicação genérica de como funciona o programa que gerencia o feed de conteúdo. Há outras maneiras desse programa se comportar, de acordo com a necessidade da rede.

O Facebook utiliza um sistema de marketing direcionado, como uma das formas de arrecadar dinheiro. Portanto, nada impede de uma publicação aparecer com maior destaque para um usuário, não por causa de suas interações, mas por conta de uma empresa ter pago para que isso ocorra. A estrutura do programa utilizado para gerenciar o feed se encontra protegido por sigilo industrial, mesmo que fosse de conhecimento público, apresenta complexidade extrema e necessita da base de dados para entender seu comportamento, visto que se adapta de acordo com as interações, o que praticamente inviabiliza sua analise (MACHADO; MORETTO, 2015, p. 126).

Entretanto, há indícios de que o programa de gerenciamento do Facebook pode apresentar algumas tendências que não parecem ser completamente aleatórias, demonstrando certo direcionamento.

Algumas pesquisas realizadas no ano de 2015, foi constatado que usuários do Facebook que interagem com certos conteúdos ideológicos tendem a receber em seu feed esmagadora maioria de conteúdos relacionados somente com aquela ideologia política. $\mathrm{O}$ programa de gerenciamento acaba restringindo o acesso a outros conteúdos e outros pensamentos. Esse efeito acaba por isolar o usuário em uma bolha ideológica e dar impressão de que toda comunidade apresenta aquele pensamento (BAKSHY; MESSING; ADAMIC, 2015, p. 1-2). Outro estudo indica que, quando expostos a determinado conteúdo, os usuários do Facebook tendem a reagir psicologicamente aquele conteúdo, sofrendo grande influência em seu comportamento, a depender daquilo a que foi exposto (KRAMER; GUILLORY; HANCOCK, 2014, p. 1-3).

Além disso, outro fator preocupante ocorre quando algum conteúdo pago ou patrocinado aparece no feed do usuário sem que o mesmo note a diferença, confundindo sua percepção quanto a natureza da postagem. Nesse caso, para o usuário aquele conteúdo faz parte da relevância habitual de sua rede, não ficando claro que aquele conteúdo aparece de forma evidente simplesmente porque o interessado pagou para tanto. Em outros termos, o usuário é exposto a conteúdos pagos e não pagos de forma a transparecer que não diferença 
entre os mesmos, sendo todos exibidos a partir de critérios de relevância (MAIA, 2016, p. 186-188).

Essa pratica á altamente nociva para os usuários, que ficam expostos a todo o tipo de publicidade e influência, sem ao menos possuir consciência da situação. No caso de empresas interessadas em vender produtos ou divulgar suas marcas, essa prática não se mostra tão nociva em termos democráticos. Entretanto, na circunstância de entidades que visam influenciar a opinião pública e visão ideológica dos cidadãos, esse comportamento possui impacto direto no exercício da democracia, alterando o ponto de vista dos cidadãos de forma incisiva, sem que os mesmos possuam sequer consciência do ocorrido.

Com o exposto fica evidente que as redes sociais não possuem preocupação com o interesse público, mas com interesse econômico. Dito isso, a forma de apresentação de seu conteúdo pode variar de acordo com diversos fatores. Um dos fatores mais preocupantes, para a questão democrática, se apresenta no campo de empresas ou partidos políticos investirem para que seu conteúdo seja apresentado de forma mais evidente ao usuário. Em relação as empresas, por conta de o conteúdo de seu interesse ficar em evidência e acabar por criar a impressão de senso comum na sociedade em determinados assuntos, que favoreçam seus interesses em termos de aprovação de legislações e formulação de políticas públicas. Em relação aos partidos políticos, por conta da execução de campanhas eleitorais desiguais e da falsa sensação de aprovação popular de suas gestões ou apenas de conteúdo que enalteça seus candidatos.

Nesse cenário, a falta de preparo e capacidade da sociedade, principalmente a brasileira, fica em sério risco frente a tais influências. Essa forma de "ajustar" o conteúdo pode modificar os rumos da sociedade e até definir as eleições dos representantes do povo, comprometendo todo o processo democrático.

\subsection{A UTILIZAÇÃO DE CONTAS AUTOMATIZADAS}

A terceira dificuldade do ambiente digital possui relação com a utilização de contas automatizadas para atuar nas redes. Essa ferramenta serve para diversos objetivos dentro do mundo virtual, podendo atuar desde a facilitação ao atendimento a clientes das grandes empresas, bem como disseminador de conteúdos de interesses privados.

Revista de Teorias da Democracia e Direitos Políticos | e-ISSN: 2525-9660 | Porto Alegre | v. 4 | n. 2 |

p. $23-44$ | Jul/Dez. 2018 
As contas automatizadas, ou robôs, seriam aquelas "controladas por software que geram artificialmente conteúdo e estabelecem interações com não robôs", buscando e imitar o comportamento através da interferência em debates e criação de conteúdo irreal (RUEDIGER et al., 2017, p. 9). Segundo levantamento realizado pela Fundação Getúlio Vargas, em importante estudo na área, as contas controladas por software atuam de forma relevante nas redes e influenciam em diversos debates em momentos chave para a sociedade brasileira. Esse tipo de intervenção tem sido utilizado de forma ativa em questões políticas, para acumular seguidores, atacar oponentes e massificar questões de pouca relevância. Todo o tipo de estratégia é utilizado para cumprir objetivos, desde replica de comentários em larga escala até ataques a discussões que lhe são desfavoráveis. Para exemplificar, essa atuação representou $10 \%$ das manifestações do twitter e de quase $20 \%$ dos apoiadores de Aécio Neves nas eleições de 2014, bem como mais $20 \%$ dos apoiadores de Dilma no processo de impeachment. A atuação das contas automatizadas (ou robôs) constitui uma ameaça ao processo democrático, pois manipula o debate político e forjar opiniões públicas, influenciando de forma fictícia a formação da vontade popular (RUEDIGER et al., 2017, p. 6-7)

A grande questão que envolve a utilização desses robôs, no ambiente das redes sociais, diz respeito à impossibilidade de saber ao certo a identidade das contas e quando um debate possui grande repercussão por ser de grande interesse da sociedade ou por interesse de quem controla essas contas automatizadas. Essa identificação, já se mostra quase impossível para indivíduos bem informados e habilidades para utilizar as redes, para aqueles que possuem baixa instrução e alta vulnerabilidade se torna uma tarefa inviável.

Outro ponto problemático a partir da utilização de robôs é divulgação de notícias falsas ou imparciais. Esse ponto se torna relevante por conta de a maioria da população mundial estar passando a acessar informações por meio virtual. Segundo levantamento da FGV, a maioria dos norte americanos, 62\%, colhe informações por meio das redes sociais, enquanto no Brasil o número é de $49 \%$, com crescimento acelerado. (RUEDIGER et al., 2017, p. 9).

Nesse cenário, a proliferação de informações falsas ou tendenciosas, por meios de robôs, possui amplas possibilidades de atingir e influenciar uma grande massa da população, que se encontra despreparada e sem defesas para lidar com esse tipo de ataque.

Revista de Teorias da Democracia e Direitos Políticos | e-ISSN: 2525-9660 | Porto Alegre | v. 4 | n. 2 | p. $23-44$ | Jul/Dez. 2018 
Com essa atuação, os robôs passam a manipular a população através da criação fictícia de apoio ou rejeição a ideias, partidos ou políticos, de acordo com os interesses de seus controladores. Muitas vezes geram certa "fama virtual" a indivíduos e assuntos que não a possuem no mundo real, mas que são favorecidos por essa ideia sugestionada na rede. $\mathrm{O}$ mesmo acontece com opiniões e teses, que não possuem relevância ou representatividade, mas que são impulsionadas por uma grande repercussão artificial. Esse processo pode servir para alavancar candidatos políticos ou criar sensos comuns que poderão nortear a sociedade, sem que a mesma compartilhe de forma real daquela ideia. Por outro lado, esse tipo de conta pode intervir para sufocar pensamentos e debates com real aceitação ou relevância a sociedade como um todo, através de ataque aquele debate ou simplesmente insistência massiva em outros assuntos (RUEDIGER et al., 2017, p. 9-10).

Esse problema pode ser identificado na prática através de questões políticas do País. O primeiro caso, das eleições de 2014, o evento foi marcado por acirrados debates políticos na rede, sendo $11 \%$ desses debates foram identificados como iniciados por robôs. No caso da ex-presidente Dilma Rousseff, apesar de toda a revolta popular vista na Copa do Mundo de Futebol de 2014 e no cotidiano da vida real, o ambiente virtual ainda registrava algum apoio a esse governo, foi detectado que $21,43 \%$ do apoio a presidente foi proveniente de contas automatizadas. Em outro caso, da greve geral de 2017, foi constatado que 22,39\% dos apoiadores da greve partiam de robôs. No terceiro caso, da reforma trabalhista, as contas automatizadas atuaram em $3 \%$ das interações contrárias a reforma e em $1 \%$ das interações favoráveis a reforma (RUEDIGER et al., 2017, p. 17-23).

Da mesma forma que a manipulação do feed, a utilização de contas automatizadas para manipulação de conteúdo se mostra com enorme potencial nocivo ao exercício democrático. Fica evidente que o uso dessa ferramenta pode influenciar nesse exercício em diversos aspectos. O primeiro diz respeito a implantação e disseminação de informações inverídicas, que pode alavancar uma candidatura ou impossibilitar outra, através do enaltecimento ou da difamação de candidatos e partidos. De igual maneira, pode criar apoios e sensos comuns artificiais, que podem influenciar diretamente a opinião da sociedade de forma falsa. O segundo diz respeito a divulgação excessiva de informações que favoreçam a certos seguimentos, que apesar de serem verídicas, não teriam um alcance amplo caso fossem compartilhadas apenas por usuários reais. Outro aspecto é a disseminação apenas de 
informações em um sentido, que acaba por isolar os usuários em uma única linha de pensamento. Em outras palavras, o uso desse tipo de conta cria um acúmulo de informações as quais o usuário é exposto, que quase inviabiliza a avaliação das mesmas.

\subsection{POLÍTICA DIRECIONADA (CASO DA CAMBRIDGE ANALYTICA)}

Um caso interessante foi o das eleições norte-americanas de 2016, que consagrou Donald Trump como presidente dos Estados Unidos. Após a eleição, foi exposto um problema ocorrido que envolve o uso da tecnologia e redes sociais, o uso de dados de usuários para direcionar a campanha política.

Em termos gerais, o caso trata da venda de uma pesquisa acadêmica para uma empresa de consultoria política, de nome Cambridge Analytica. Essa empresa auxilio a campanha de Donald Trump para a referida eleição, se utilizando da pesquisa para organizar campanha na internet. Acontece que a pesquisa tinha como objetivo traçar perfis dos usuários das redes sociais, através de sua interação no Facebook, possuindo interesse público antes da venda. Através desses dados, se tornou possível direcionar o envio de mensagens de conteúdo político, construindo seu conteúdo de acordo perfil político do usuário. Esse método permitiu que as mensagens que chegavam ao cidadão possuíssem apenas conteúdo que os mesmos concordassem, favorecendo a simpatia ao candidato. $\mathrm{O}$ uso dessa tecnologia permitiu atingir por volta de 80 milhões de usuários, sendo considerado um fator de influência direto na eleição de Trump (ZANATTA, 2018, p. 13).

Desta situação podemos ressaltar dois pontos importantes para a reflexão. O primeiro diz respeito à utilização dados coletados a partir de interação pessoal dos usuários com a rede social. Em que pese a rede Facebook possuir natureza privada e visar lucro, o uso desses dados pessoais para fins comerciais e de modo a influenciar na escolha política dos cidadãos parece ser uma enorme invasão de privacidade dos usuários e infringir a ética. Cada ação dos usuários passa a estar livremente disponível para o conhecimento de todos, principalmente, para a utilização contra o próprio usuário, manipulando suas convicções.

O segundo ponto é a ser ressaltado é o poder de influência que os atores políticos passam a possuir em suas campanhas. Nesse cenário, o candidato não precisa formular um plano de governo robusto e que vise atender a maioria dos interesses de seus eleitores,

Revista de Teorias da Democracia e Direitos Políticos | e-ISSN: 2525-9660 | Porto Alegre | v. 4 | n. 2 |

p. $23-44$ | Jul/Dez. 2018 
bastando ter recursos para pagar o acesso aos dados e impulsionar mensagens para grupos de usuários, de acordo as convicções dos mesmos. Em outras palavras, não se faz mais necessário investir em plataformas políticas coerentes, mas sim, em bases de dados que possibilitem mandar conteúdos apropriados para as pessoas certas, mesmo que as diversas mensagens sejam contraditórias.

\section{CONCLUSÃO}

Diante do exposto, a democracia pode ser definida como um conceito que varia para cada sociedade, pressupondo a autodeterminação dos cidadãos, a correspondência das decisões políticas com os anseios da sociedade e a prevalência do interesse público. $\mathrm{O}$ exercício adequado dessa democracia, a partir de Amartya Sen, requer que sejam conferidas as condições necessárias aos cidadãos para seu desempenho. Esse pensamento engloba o acesso da população a instrução básica, escolaridade, acesso a meios de debates políticos, amplo acesso a informações verdadeiras, e capacidade de intervir nas decisões políticas e na formação de uma opinião livre de influências e barreiras. Em outros termos, não basta o simples acesso ou positivação (exercício formal da democracia), se faz necessário também proporcionar as condições adequadas para o exercício substancial da democracia.

A população brasileira, normalmente, já convive com enormes deficiências nas condições para atuar no campo democrático, por questões de falta de educação, de possibilidades econômicas, corrupção e crise de representatividade. Essa situação parecer ser agravada pelo uso das redes sociais, diante de diversas dificuldades.

A primeira é que, apesar do amplo potencial de interação que a Internet apresentou, a mesma não revolucionou o comportamento da sociedade, apenas potencializou e expandiu o existente. A rede possui diversas possibilidades de interação como acesso direto e rápido da população com seus representantes; facilidade na fiscalização das atividades estatais, com a possibilidade de divulgação de informações de interesse público o cidadão seria capaz de participar ativamente da vida política; e a possibilidade de contato entre os cidadãos, facilitando os debates públicos e a mobilização social. Entretanto, o cenário apresentado foi de que aqueles que possuem influência social apenas aumentaram seu alcance, e os demais viraram meros reprodutores de conteúdo.

Revista de Teorias da Democracia e Direitos Políticos | e-ISSN: 2525-9660 | Porto Alegre | v. 4 | n. 2 | p. $23-44$ | Jul/Dez. 2018 
Outro ponto, é que a liberdade de acesso a Internet não se traduz em participação do cidadão na democracia, se não for houver capacidade para o uso. A capacidade aqui é empregada como uma espécie de formação básica para utilizar a Internet, tanto na aprendizagem de utilização da ferramenta quanto no entendimento mínimo da como o conteúdo é apresentado. Esse conceito se relaciona com preparação e habilidades mínimas, para evitar a utilização precária da ferramenta, que deixa o indivíduo sem defesas para os conteúdos, influências e "verdades absolutas artificiais". Logo, se não houver preparo, o indivíduo não estará apto a participar de forma influente e real na democracia do Brasil.

A terceira dificuldade diz respeito a que as redes sociais possuem interesse privado e econômico. Dessa forma, a apresentação de seu conteúdo não possui preocupação com questões de igualdade, por não atender ao interesse público, mas sim atender aos seus interesses privados/econômicos. O conteúdo é apresentado com base em diversas variáveis, desde o número de curtidas e compartilhamentos até os assuntos com os quais o usuário interage com maior frequência. Nesse sentido, nada impede que uma empresa negocie com a rede social para expor sua marca com maior evidência ou que um partido político realize um acordo para beneficiar as publicações de seus candidatos. Assim, diversos agentes podem atuar livremente para favorecer ou destacar seu conteúdo na rede, influenciando de forma direita a opinião dos cidadãos, bem como sua percepção sobre os anseios da sociedade. Essa atuação pode levar a aprovação de legislações com interesses privados, eleição de representantes que não possuem apoio popular, influência eleitoral desleal, falsos sensos comuns, entre outros.

Uma quarta dificuldade se relaciona com a existência de contas automatizadas (ou robôs) na rede, que criam situações artificiais. Essas contas seriam as controladas por softwares para interagir na rede, simulando a participação de pessoas reais, com o intuito de ludibriar os usuários. Pesquisas realizadas apontam o uso dessa ferramenta em diversos marcos políticos importantes do país, tanto para apoiar quanto para difamar candidatos e ideias. Essas ferramentas podem ser utilizadas de diversas maneiras, tanto para disseminar informações falsas, quanto para criar senso comum ou vontade popular artificiais, bem como para poluir a rede com multiplicação de postagens que favoreçam uma vertente ou ideia.

A quinta dificuldade encontra foi o uso de dados dos usuários para envio de conteúdo direcionado, de acordo com seu perfil de interação nas redes, como no caso da Cambridge 
Analytica na eleição de Donald Trump nos Estados Unidos. Essa prática possibilita o envio de mensagens com conteúdos diferentes, e até mesmo conflitantes, para usuários, de acordo com suas convicções ideológicas. Assim, o candidato consegue reunir eleitores dos mais diversos segmentos, mesmo que não concordem com sua conduta política ou ideologia, simplesmente porque recebeu a mensagem com palavras condizentes com suas ideias.

Assim, as últimas dificuldades, aliadas a falta de capacidade para se inserir nesse contexto, deixa o cidadão brasileiro suscetível a todas essas influências, comprometendo sua habilidade de participar do processo democrático. Portanto, se em países desenvolvidos, como os Estados Unidos, já houve comprovada influência na democracia, países subdesenvolvidos, como o Brasil, possuem maior suscetibilidade as dificuldades apresentadas neste estudo, principalmente pela ausência de autodeterminação de seu povo.

Assim, utilizando as teorias de Jürgen Habermas e Ronald Dworkin (autodeterminação dos povos) em conjunto com a teoria de Amartya Sen (condições necessárias), podemos definir que para o exercício adequado da democracia é imprescindível que estejam presentes as condições necessárias para tanto, sendo a autodeterminação dos povos uma delas. Diante das dificuldades apresentadas ao longo do estudo, fica evidente que o exercício da democracia substancial no cenário digital brasileiro se mostra inviável. Logo, apesar de apresentar um acesso razoável ao exercício formal da democracia, o País apresenta graves obstáculos ao exercício substancial da democracia nas redes, se apresentando como uma ilusão digital.

\section{REFERÊNCIAS}

BAKSHY, Eytan; MESSING, Solomon; ADAMIC, Lada. Exposure to ideologically diverse news and opinion on Facebook. Science, v. 348, n. 6239, p. 1130-1132, 2015.

BRISOLA, Anna Cristina Caldeira de Andrada. A ágora digital, a competência crítica em informação e a cidadania ampliada: uma construção possível. Dissertação de MestradoRio de Janeiro: Universidade Federal do Rio de Janeiro, 2016.

CASTELLS, Manuel. A política da internet I: redes de computadores, sociedade civil e o Estado. A galáxia da internet: reflexões sobre a internet, os negócios e a sociedade. Rio de Janeiro: Jorge Zahar, 2003.

DWORKIN, Ronald. Justiça para ouriços. Coimbra: Almedina, 2012. 
HABERMAS, Jürgen. Direito E Democracia: Entre Facticidade E Validade. Rio de Janeiro: Tempo Brasileiro, 1997.

KRAMER, Adam; GUILLORY, Jamie; HANCOCK, Jeffrey. Experimental evidence of massive-scale emotional contagion through social networks. Proceedings of the National Academy of Sciences, 2014.

MACHADO, Jorge; MORETTO, Márcio. Riscos e incertezas do uso do Facebook como plataforma de ativismo político. Cadernos Adenauer XVI, n. 3, p. 113-132, 2015.

MAIA, Maíra Carneiro Bittencourt. O príncipe digital: estruturas de poder, liderança e hegemonia nas redes sociais. Universidade de São Paulo, 2016.

RUEDIGER, Marco Aurélio; et al. Robôs, redes sociais e política no Brasil: estudo sobre interferências ilegítimas no debate público na web, riscos à democracia e processo eleitoral de 2018. 2017.

SEN, Amartya. Desenvolvimento como liberdade. São Paulo: Companhia das Letras, 2000.

ZANATTA, Rafael. Fake news e o triunfo do reducionismo. Revista Instituto Humanitas Unisinos, v. Ano XVIII, n. No 520, 2018. 